\title{
Microbial Communities Involved in Methane Production from Coal Treated by Potassium Permanganate
}

\author{
Hongguang Guo ${ }^{1}$, Qiurong Wang ${ }^{2}$, Michael A Urynowicz ${ }^{3,4}$, Paul Fallgren ${ }^{5}$, Song Jin ${ }^{3,5}$, Rizwan Haider ${ }^{3}$ and Zaixing \\ Huang ${ }^{4,6 *}$ \\ ${ }^{1}$ College of Mining Technology, Taiyuan University of Technology, China \\ ${ }^{2}$ Department of Animal Science, University of Wyoming, Laramie, USA
}

${ }^{3}$ Department of Civil and Architectural Engineering, University of Wyoming, USA

${ }^{4}$ Center for Biogenic Natural Gas Research, University of Wyoming, USA

${ }^{5}$ Advanced Environmental Technologies LLC, Fort Collins, USA

${ }^{6}$ Department of Chemical and Petroleum Engineering, University of Wyoming, USA

*Corresponding author: Zaixing Huang, Department of Chemical and Petroleum Engineering, University of Wyoming 82071, USA

Submission: 筒 February 15, 2018; Published: 眥 March 09, 2018

\begin{abstract}
Coal bed natural gas (CBNG) or coal bed methane (CBM) is considered as an untapped energy resource and accounts for over 3\% of total natura gas produced in the US in 2016. Nature gas burns cleaner than coal and has been suggested as a "bridging fuel" to transition away from coal. In recent decades, scientific discoveries have demonstrated that in many of the world's CBNG plays, the gas is biogenic in origin. The fact that coal is rich in organic carbon is found attractive, and recent studies suggest that biogenic coal bed natural gas can be enhanced through methods including bio-stimulation, bio-augmentation, chemical pre-treatment and supplement of external carbon sources. One of the key elements for coal-based methane production is the microbial populations that are capable of decomposing and transforming coal-derived organic compounds to methane. In this study, we first reported the identification of microbial communities of coal treated by permanganate for enhanced methane production. The results demonstrate that microbial communities involved in the bio-transformation of coal-derived carbon to methane are highly diverse. In addition, hydrogenotrophic methanogenesis appears to be the dominant pathway in producing biogenic natural gas in the samples used for this study. These findings may not only increase the understanding of operative mechanisms behind these complex transformations but also help in exploitation and optimization of field scale production of CBNG.
\end{abstract}

Keywords: Biogenic Methane, Coal bed Methane (CBM), Coal bed Natural Gas (CBNG), Microbial Communities In Coal, Permanganate

\section{Introduction}

Coal bed natural gas (CBNG) or coal bed methane (CBM), being an unconventional natural gas source, is naturally adsorbed in coal bed under hydrostatic and overburden pressure [1]. In the global effort of switching to low-carbon fuels, CBNG represents an alternative fuel option as an untapped yet clean energy resource [2]. The global deposit of CBNG is estimated to prominent 53.3 trillion cubic meters (Tcm) [3]. The global production of CBNG between 2000 to 2014 is shown in Figure 1 [4]. The United States is the leading CBNG producer, comprising over $50 \%$ of the total production in 2014, followed by China, 21\%; Australia, $11 \%$; and Canada, $10 \%$. Natural gas burn cleaner than coal as it emits no other constituents than $\mathrm{CO}_{2}$, and roughly half of $\mathrm{CO} 2$ on a per unit energy production when compared to coal [5].
On the basis of its genesis, CBNG may have two origins: biogenic and thermogenic. It can be distinguished by chemical analysis and isotopic signatures [6-8]. However, on the basis of occurrence, blends with varied compositions of thermogenic and biogenic CBNG may be experienced [9]. Thermogenic CBNG is generated through the cracking of organic carbons typical associated with high temperature during late coalification processes $[8,10]$. Biogenic CBNG is produced by decomposition of organic matter by microorganisms living in the coal seams [8]. The biogenic gas produced prior coalification is termed as the primary gas and likely to be lost during the compaction and coalification processes. Secondary biogenic gas is referred to the gas produced at post coalification stage. 


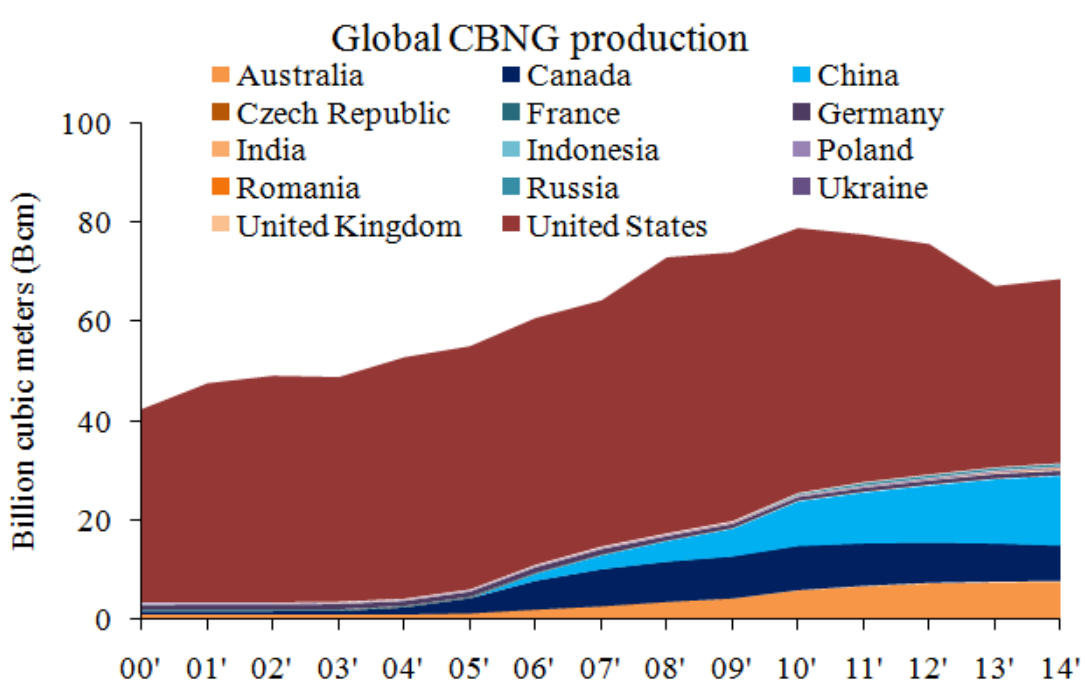

Figure 1: CBNG production in the world, 2000-2014 [4]. The United States, China, Australia and Canada are the leading producers and produced $96.5 \%$ CBNG in the world.

Coal is a carbonaceous rock that contains over $50 \%$ by weight or more than $70 \%$ by volume organic carbon [11]. It can potentially provide the carbon source to microorganisms indigenous to coal. However, coal is heterogeneous and hydrophobic in characteristics, which makes it recalcitrant to common microbial degradation5. Traditionally, two main approaches may be deployed to enhance the production of CBNG, i.e., bio-stimulation and bio-augmentation $[12,13]$. Bio-stimulation is to stimulate indigenous microbial growth by adding supplement compounds and nutrients while bio-augmentation is to add external microbial consortia $[5,12]$. However, the bioavailability of the carbon in the majority of coal, especially higher grade coal, was found to be less bio-amenable to the production of CBNG $[14,15]$. Physiochemical approaches have been attempted to improve the bioavailability of coal-derived carbon for transformation into methane [2,14,16-18]. However, the microbial activities involved in CBNG generation in coal, especially coal that went through enhancing treatment, are not well understood. This study investigated microbial communities involved in methane production from the Powder River Basin sub-bituminous coal treated by permanganate (coal residues and liquid). To the best of our knowledge, this is the first report on microbial communities involved in the enhanced production of CBNG by treating with permanganate.

\section{Materials and Methods}

\section{Coal and microcosms}

Coal: Coal cores were sampled from borehole SL-5 within Fort Union Formation of Powder River Basin (PRB). The detailed information of the sampling site, geologic information, and lithology records can be found in Huang et al. [16]. The coal sample is sub-bituminous in rank. The elemental composition of the coal is as following: $65.20 \% \mathrm{C}, 3.65 \% \mathrm{H}, 14.07 \% \mathrm{O}, 1.24 \% \mathrm{~N}$, and $3.57 \%$ S. Coal was ground to pass through 60 mesh sieve. The fraction of coal passing the sieve $(200 \mathrm{mesh})$ was treated by $0.1 \mathrm{M} \mathrm{KMnO} 4$ at ambient temperature for 21 days. The liquid fraction was separated from the residual solid coal. Both liquid fraction and residual coal, separately, were used for microcosm preparation. The liquid samples were characterized using total organic carbon (TOC) analyzer, GC/MS, and 3-dimensional excitation emission matrix fluorescence spectroscopy (3D-EEM). Please refer to Huang et al. [19] for detailed information.

Microcosms: The readers are requested to consult the details of microcosm setup in Huang et al. [19]. Briefly, microcosms were set up using $160 \mathrm{ml}$ serum bottle in anaerobic chamber. Each serum bottle was loaded with either liquid fraction or residual coal after KMnO4treatment equivalent to 1gram coal. The medium consisted of mineral, trace metal and vitamin was prepared according to Hurst et al. [20]. A coal derived microbial consortium was used as the inoculum. Coal containing microorganisms were enriched with $10 \mathrm{~g} / \mathrm{L}$ urea before inoculation. A volume of $0.5 \mathrm{ml}$ (less than $1 \%$ of the total culture volume) of inoculum was added to each of the bottles. The microcosms were incubated at $30{ }^{\circ} \mathrm{C}$. The gas composition of headspace in serum bottle was analyzed by a gas chromatograph. The liquid samples are designated as PL while coal residues are designated as $\mathrm{PC}$.

\section{DNA extraction and miseq sequencing and analysis}

Coal was first pulverized and washed using a $0.05 \mathrm{M}$ sterile phosphate buffer ( $\mathrm{pH} 7.4$ ) containing $0.2 \%$ Tween 80 as described previously $[21,22]$ to elute the microorganisms attached to the surface of coal and eliminate any interference of heavy metals which might reduce the efficiency of DNA extraction. After washing, the solutions were filtered through a $0.22-\mu \mathrm{m}$ membrane filter (Whatman, Japan). The filter was used for DNA extraction with a Fast DNA SPIN kit for soil (Bio101 Systems, Carlsbad, USA) according to the manufacturer's instructions. DNA quality and concentration was determined using a Nano drop TM 1000 Spectrophotometer (Nano drop, Wilmington, DE, USA) and agarose gel electrophoresis. The obtained DNA was stored at $-20^{\circ} \mathrm{C}$ for further processing. 
DNA sequencing was performed by the Institute for Environmental Genomics at the University of Oklahoma with an Illumina Miseq platform (San Diego, CA, USA). The protocol of $\mathrm{PCR}$, sequencing and data analysis were performed as described previously [21,22]. Briefly, the 16S r RNA variable region 4 (V4) were amplified using the universal primer sets $515 \mathrm{~F} / 806 \mathrm{R}$ (GTGCCAGCMGCCGCGGTAA/GGACTACHVGGGTWTCTAAT) which have been used for Illumina-based surveys to amplified bacterial and archaeal 16S r RNA genes [22]. The raw sequence reads were processed by an in-house sequence analysis pipeline (IEG sequence analysis pipeline). Btrim was used to complete the quality trimming with minimum length of $150 \mathrm{bp}$, average quality score of 25 , and removing sequencing adaptors. Forward and reverse reads were combined using FLASH. Chimeric sequences were removed using UCHIME. The operational taxonomic units (OTUs) were classified using UCLUST at the $97 \%$ similarity level, and singletons were removed. The taxonomic assignment was conducted by RDP classifier with minimal 50\% confidence estimates. The 16S r RNA gene sequences derived from Miseq pyro sequencing has been deposited in the NCBI Sequence Read Archive with the accession numberSUB3678654.

\section{Results and Discussion}

\section{Summaries of chemical treatment and gas production [19]}

Potassium permanganate is an effective oxidant with a redox potential of 1.67 [5]. The chemical treatment by permanganate produced TOC as high as $1181.1 \mathrm{mg} / \mathrm{l}$, which accounted $5.4 \%$ of the original coal carbon. Three peaks were identified in the 3D-EEM analyses, referring to the presence of humic-like, fulvic-like and aromatics/PAHs-like compounds. The liquid fraction of the coal sample contained a small volatile fraction, most of which were single ring aromatics as revealed by GC/MS analyses. Both liquid samples (PL) and coal residues (PC) showed $\mathrm{CO} 2$ production. However, methane production was only observed in the microcosms enriched with liquid fraction of the coal samples. The methane generation, thus, showed that the organic substrates contained in the liquid fraction were readily available to microorganisms. The accumulation of methane was detected as early as 4 days and peaked at day 40 . The mean concentration of methane was $93.4 \mu \mathrm{mol} / \mathrm{g}$ coal, representing $3.2 \%$ of TOC.
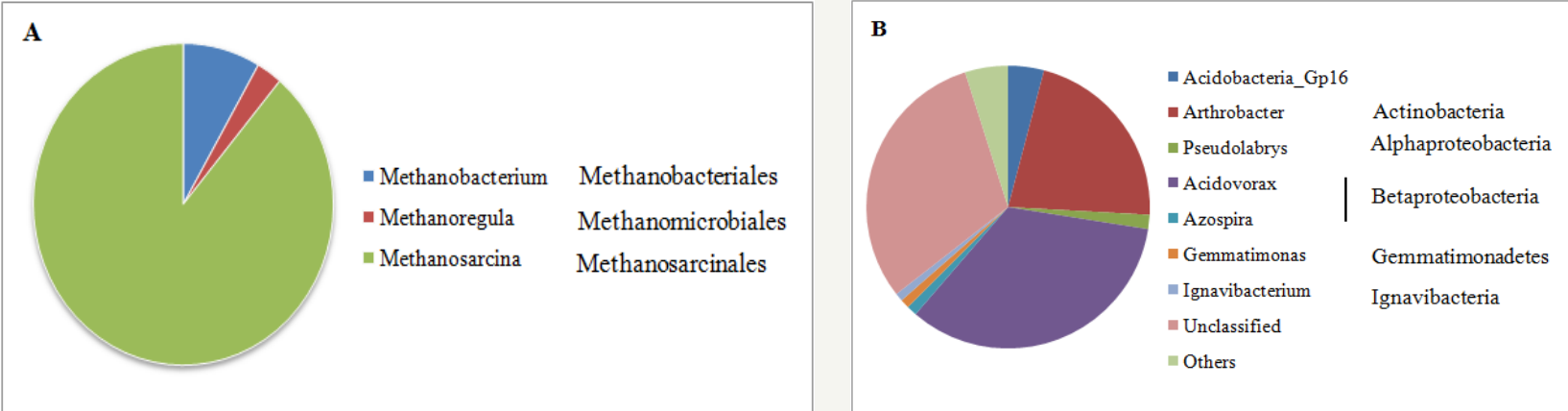

Figure 2: Archaeal (A) and bacterial (B) communities in PC samples at genetic level. All the archaeal genera were shown while only the bacterial genera accounting for $>0.5 \%$ of sequence reads were shown. The rest bacterial genera were grouped into "Others".s

\section{Microbial community analyses}

A total of 5390 sequence reads were obtained from PC sample after quality control, which included 5354 bacterial sequence reads with 126 OTUs and 36 archaeal sequence reads with 4 OTUs. A total of 31482 sequence reads were obtained from PL sample, which included 30640 bacterial sequence reads with 1034 OTUs and 842 archaeal sequence reads with 24 OTUs. The microbial diversity of PL sample appeared to be significantly higher than that of PC sample from the perspective of recovered sequence read number and OTUs number. The limited bacterial and archaeal communities in the PC samples might be the reason to that no methane was produced.

The taxa of archaeal and bacterial communities in the PC samples are shown in Figure 2. All the archaeal sequence reads belong to methanogen (Figure 2A). Only three methanogenic genera were detected in sample PC, including Methanobacterium (8.33\%), Methanoregula (2.78\%), and Methanosarcina (88.89\%). Methanobacterium is obligate hydrogenotrophic methanogen [23]. Methanoregula can produce methane from $\mathrm{H}_{2} / \mathrm{CO}_{2}$ [24].
Methanosarcina, however, can utilize diverse substrates and produce methane via all three methanogenesis path ways, i.e., acetoclastic, hydrogenotrophic and methylotrophic. Although methanogens were detected after cultivation, no methane was produced or methane yield was below the detection limit. The similar phenomenon was also reported by Ohtomo et al. [25], where methanogens were obtained from batch-type cultivation, no methanogens, however, were activated during experiment in the reactor system.

For bacterial communities, Proteobacteria was observed to be the predominant phylum with $51.48 \%$ of the sequence reads, which consistent with some previous findings related to methanogenic communities for coal biodegradation [22] (Figure 2B). Specifically, $33.83 \%$ of sequence reads were classified into Acidovorax which was the dominant genus detected. Pseudolarys and Azospira accounted for $1.62 \%$ and $1.18 \%$ of sequence reads, respectively. The proportion of sequence reads in other genera in Proteobacteria was all below $0.5 \%$. The second dominant phylum was Actinobacteria 
with $21.91 \%$ of sequence reads, in which $21.78 \%$ of sequence reads, were grouped into the genus Arthrobacter. Other primary phyla were Acidobacteria (4.65\% of sequence reads), Chloroflexi $(4.02 \%$ of sequence reads), and Gemmatimonadetes $(1.05 \%$ of sequence reads). Acidobacteria_Gp16, accounting for $4.09 \%$ of sequence reads was the main genus in Acidobacteria. Most of the sequence reads in Chloroflexi could not be classified into any known genus. All the sequence reads in Gemmatimonadetes were grouped into only one genus, Gemmatimonas. Ignavibacterium also accounted for more than $0.5 \%$ of sequence reads.
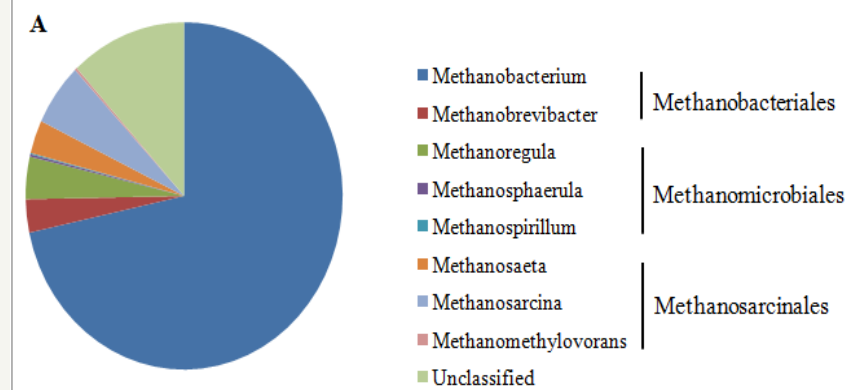

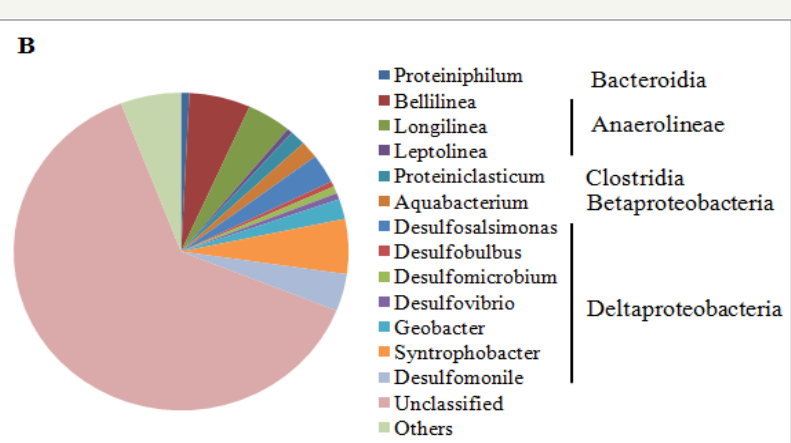

Figure 3: Archaeal (A) and bacterial (B) communities in PL samples at genetic level. All the archaeal genera were shown while only the bacterial genera accounting for $>0.5 \%$ of sequence reads were shown. The rest bacterial genera were grouped into "Others".

The taxa of archaeal and bacterial communities in the PL samples are shown in Figure 3. All the archaeal sequence reads were classified into Euryarchaeota, which include Methanobacteria (74.70\% of sequence reads), Methanomicrobia (13.42\% of sequence reads), and Thermoplasmata (11.88\% of sequence reads). Specifically at genetic level (Figure 3A), 71.62\% of sequence reads belonged to Methanobacterium. $5.82 \%$ of sequence reads were classified into Methanosarcina. Methanoregula, Methanobrevibacter, and Methanosaeta respectively account for $3.92 \%, 3.09 \%$, and $3.09 \%$ of sequence reads. The proportions of sequence reads in Methanosphaerula, Methanomethylovorans, and Methanospirillum were all below 0.3\%.Compared with PC samples, more diversity in methanogens was observed in the PL samples. All the genera detected in the PC samples were also found in the PL samples with different proportions. Most of methanogens were hydrogenotrophic, such as Methanobacterium, Methanobrevibacter [26], Methanoregula [24], Methanosphaerula [27], Methanospirillum [28], which accounted for almost $80 \%$ of the sequence reads. Methanosarcina can also utilize $\mathrm{H}_{2}$ and $\mathrm{CO}_{2}$ to produce methane. Although acetoclastic and methylotrophic methanogens were also found, e.g. Methanosaeta [29] and Methanomethylovorans [30], they only consisted of approximately $4 \%$ of the sequence reads, suggesting the production of methane by mainly hydrogenotrophic methanogenesis [31-38].

\section{Acknowledgement}

Funding for this project was provided by RPSEA through the Ultra-Deepwater and Unconventional Natural Gas and Other Petroleum Resources program authorized by the U.S Energy Policy Act of 2005.

\section{References}

1. Flores RM (2013) Coal and coalbed gas: fueling the future. Newnes.

2. Gallagher LK, Andrew W Glossner, Lee L Landkamer, Linda A Figueroa, Kevin W Mandernack et al. (2013) The effect of coal oxidation on methane production and microbial community structure in Powder River Basin coal. International Journal of Coal Geology 115: 71-78.

3. Andruleit $\mathrm{H}$ et al. (2016) (ed. F.I.f.G.a.N.R. (BGR)), Hannover, Germany, Europe.

4. IEA (2018) Unconventional gas production database. France, Europe.

5. Huang Z (2014) Biogenic Natural Gas: An evaluation of pre treatment agents for the stimulation of secondary biogenic natural gas. Scholars' Press, Saarbrücken, Germany, Europe.

6. Rice DD, Claypool GE (1981) Generation, accumulation, and resource potential of biogenic gas. AAPG Bulletin 65(1): 5-25.

7. Rice DD (1993) Composition and origins of coalbed gas. Hydrocarbons from coal: AAPG Studies in Geology 38: 159-184.

8. Scott AR, Kaiser W, Ayers WB (1994) Thermogenic and secondary biogenic gases, San Juan basin, Colorado and New Mexico--implications for coal bed gas producibility. AAPG bulletin 78 (8): 1186-1209.

9. Ayers WB (2002) Coal bed gas systems, resources, and production and a review of contrasting cases from the San Juan and Powder River basins. AAPG bulletin 86(11): 1853-1890.

10. Scott AR (2002) Hydrogeologic factors affecting gas content distribution in coal beds. international Journal of coal geology 50(1-4): 363-387.

11. Morton SJ (1956) A definition of coal. Economic Geology 51: 521-527.

12. Park SY, Liang Y (2016) Biogenic methane production from coal: a review on recent research and development on microbially enhanced coalbed methane (MECBM) Fuel 166: 258-267.

13. Ritter D, DavidVinson, ElliottBarnhart, Denise Akob M, Matthew Fields W, et al. (2015) Enhanced microbial coalbed methane generation: a review of research, commercial activity, and remaining challenges. International Journal of Coal Geology 146: 28-41.

14. Huang Z, Urynowicz M (2015) Enhanced production of biogenic coal bed methane from coals following chemical oxidation. Abstracts of papers of the American Chemical Society 249 (Amer Chemical Soc $115516^{\text {th }}$ St, Nw, Washington, DC 20036 USA.

15. Strąpoć D, Flynn Picardal W, Courtney Turich, Irene Schaperdoth, Jennifer Macalady L, et al. (2008) Methane-producing microbial community in a coal bed of the Illinois Basin. Applied and environmental microbiology 74(8): 2424-2432. 
16. Huang Z, Urynowicz MA, Colberg PJ (2013) Bioassay of chemically treated subbituminous coal derivatives using Pseudomonas putida F1. International Journal of Coal Geology 115: 97-105.

17. Jones EJ, Voytek MA, Corum MD, Orem WH (2010) Stimulation of methane generation from nonproductive coal by addition of nutrients or a microbial consortium. Appl Environ Microbiol 76(21): 7013-7022.

18. Harris SH, Smith RL, Barker CE (2008) Microbial and chemical factors influencing methane production in laboratory incubations of low-rank subsurface coals. International Journal of Coal Geology 76(1-2): 46-51 (2008)

19. Huang Z, Urynowicz MA, Colberg PJ (2013) Stimulation of biogenic methane generation in coal samples following chemical treatment with potassium permanganate. Fuel 111: 813-819 (2013).

20. Hurst CJ, Crawford RL, Garland JL, Lipson DA (2007) Manual of environmental microbiology. (American Society for Microbiology Press, Washington, USA.

21. Guo H, Jinlong Zhang, Qing Han, Zaixing Huang, Michael Urynowicz A et al. (2017) Important role of fungi in the production of secondary biogenic coalbed methane in China's Southern Qinshui Basin. Energy \& Fuels 31(7): 7197-7207.

22. Huang Z, Sednek C, Urynowicz MA, Guo H, Wang Q, et al. (2017) Low carbon renewable natural gas production from coalbeds and implications for carbon capture and storage. Nature Communications 8(1): 568.

23. Kitamura K, Fujita T, Akada S, Tonouchi A (2011) Methanobacterium kanagiense sp. nov., a hydrogenotrophic methanogen, isolated from ricefield soil. Int J Syst Evol Microbiol 61(6): 1246-1252.

24. Bräuer SL, Cadillo-Quiroz H, Ward RJ, Yavitt JB, Zinder SH (2011) Methanoregula boonei gen. nov., sp. nov, an acidiphilic methanogen isolated from an acidic peat bog. Int J Syst Evol Microbiol 61(1): 45-52.

25. Ohtomo Y, Ijiri A, Ikegawa Y, Tsutsumi M, Imachi H, et al. (2013) Biological $\mathrm{CO}_{2}$ conversion to acetate in subsurface coal-sand formation using a high-pressure reactor system. Frontiers in Microbiology 4: 361.

26. Rea S, Bowman JP, Popovski S, Pimm C, Wright ADG (2007) Methanobrevibacter millerae sp. nov. and Methanobrevibacter olleyae sp. nov., methanogens from the ovine and bovine rumen that can utilize formate for growth. Int J Syst Evol Microbiol 57(3): 450-456.

27. Cadillo-Quiroz H, Yavitt JB, Zinder SH (2009) Methanosphaerula palustris gen. nov., sp. nov., a hydrogenotrophic methanogen isolated from a minerotrophic fen peatland. Int J Syst Evol Microbiol 59(5): 928935.
28. Iino T, Mori K, Suzuki K (2010) Methanospirillum lacunae sp. nov., a methane-producing archaeon isolated from a puddly soil, and emended descriptions of the genus Methanospirillum and Methanospirillum hungatei. Int J Syst Evol Microbiol 60(11): 2563-2566.

29. Liang B, Wang LY, Mbadinga SM, Liu JF, Yang SZ, et al. (2015) Anaerolineaceae and Methanosaeta turned to be the dominant microorganisms in alkanes-dependent methanogenic culture after longterm of incubation. AMB Express 5(1): 1-13.

30. Cha IT, Min UG, KimSJ, Yim KJ, RohSW, etal.(2013) Methanomethylovorans uponensis sp. nov., a methylotrophic methanogen isolated from wetland sediment. Antonie Van Leeuwenhoek 104(6): 1005-1012.

31. Schulze R, Spring S, Amann R, Huber I, Ludwig W, et al. (1999) Genotypic diversity of Acidovorax strains isolated from activated sludge and description of Acidovorax defluvii sp. nov. Syst Appl Microbiol 22(2): 205-214.

32. Gray TR, Mansoor EY (1996) The application of serological techniques to the taxonomy of Arthrobacter and related organisms. Microbiology 142 (3): 561-573.

33. Kieraitealeksandrova I, Aleksandrovas V, Kuisiene N (2015) Down into the Earth: microbial diversity of the deepest cave of the world. Biologia 70(8): 989-1002.

34. Yamada T, Imachi H, Ohashi A, Harada H, Hanada S, et al. (2007) Bellilinea caldifistulae gen. nov., sp. nov. and Longilinea arvoryzae gen. nov., sp. nov., strictly anaerobic, filamentous bacteria of the phylum Chloroflexi isolated from methanogenic propionate-degrading consortia. Int J Syst Evol Microbiol 57(10): 2299-2306.

35. Boone DR, Bryant MP (1980) Propionate-degrading bacterium, Syntrophobacter wolinii sp. nov. gen. nov., from methanogenic ecosystems. Appl Environ Microbiol 40(3): 626-632.

36. Sun B, Cole JR, Tiedje JM (2001) Desulfomonile limimaris sp. nov., an anaerobic dehalogenating bacterium from marine sediments. Int J Syst Evol Microbiol 51(2): 365-371.

37. Hahnke S, Langer T, Koeck DE, Klocke M (2016) Description of Proteiniphilum saccharofermentans sp. nov., Petrimonas mucosa sp. nov. and Fermentimonas caenicola gen. nov., sp. nov. isolated from mesophilic lab-scale biogas reactors and emended description of the genus Proteiniphilum. Int J Syst Evol Microbiol 66(3): 1466-1475.

38. Zhang K, Song L, Dong X (2010) Proteiniclasticum ruminis gen. nov., sp. nov., a strictly anaerobic proteolytic bacterium isolated from yak rumen. Int J Syst Evol Microbiol 60(9): 2221-2225.
Creative Commons Attribution 4.0 International License

For possible submissions Click Here

\section{Submit Article}

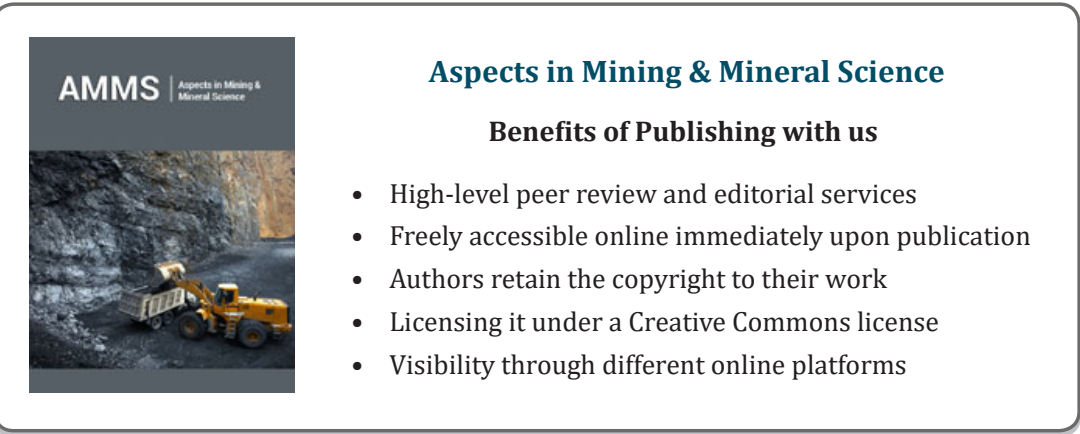

